\title{
Surgical outcome of blepharophimosis syndrome: Double vs single stage
}

\author{
Syeed Mehbub UI Kadir \\ Assistant Professor, Dept. of Ophthalmology, Sheikh Shahera Khatun Medical College, Gopalgonj, Bangladesh, Sr. Consultant, Orbit \& \\ Ophthalmic Plastic Services, Bangladesh Eye Hospital \& Institute, Bangladesh

\section{*Corresponding Author: Syeed Mehbub Ul Kadir} \\ Email: mehbubkadir@gmail.com
}

\begin{abstract}
Purpose: To assess the surgical outcome of Blepharophimosis syndrome (BPES).

Materials and Methods: This interventional study has been evaluated pre and postoperatively of fifty patients in two tertiary eye hospital in Bangladesh. All patients were divided into two groups like as group-A (35 patients) and group-B (15 patients). Telecanthus, Epicanthus and ptosis were corrected 3 months apart in group-A. All procedures were done in single setting in group-B.

Results: Male patients were $21(42 \%)$ and female patients were $29(58 \%)$. In group-A, Satisfactory outcome of Y-V plasty was $89 \%$, and $11 \%$ patient presented unsatisfactory correction of telecanthus. Under correction after ptosis surgery was observed in 02 patients. In group$\mathrm{B}$, satisfactory outcome of $\mathrm{C}-\mathrm{V}$ plasty was $93 \%$ and under correction was observed in 4 patients followed by ptosis surgery.

Conclusion: There is no significant difference between $\mathrm{Y}-\mathrm{V}$ plasty and $\mathrm{C}-\mathrm{V}$ plasty to correct telecanthus and epicanthus. Ptosis correction resulted well in separate sittings.
\end{abstract}

Keywords: Blepharophimosis syndrome, Y-V Plasty, C-V Plasty.

\section{Introduction}

Blepharophimosis syndrome is autosomal dominantly inherited disease presenting with telecanthus, epicanthus inversus and moderate to severe ptosis with poor levator function. Other findings may include lateral lower eyelid ectropion, poorly developed nasal bridge, hypoplasia of superior orbital rims, lop ears and hypertelorism. Y-V plasty or multiple $\mathrm{Z}$ plasty are used to modify the telecanthus and epicanthus. Ptosis surgery may perform simultaneously with Y-V plasty or after 3 months of $\mathrm{Y}-\mathrm{V}$ plasty. Visually disturbed ptosis should be addressed promptly. Additional procedures may be done to correct associated problems like as ectropion or hypoplasia of orbital rims. ${ }^{1,2} \mathrm{We}$ attempt to evaluate the surgical outcome of Blepharophimosis syndrome in two step surgery and in single step surgery.

\section{Materials and Methods}

This interventional study has been evaluated fifty patients of Blepharophimosis syndrome in two tertiary care eye hospitals in Bangladesh. All patients were divided into two groups like as group-A (35 patients) and group-B (15 patients). Telecanthus, Epicanthus and ptosis were corrected by double (two) stages, second surgery (ptosis correction) were done at 3 months apart in group-A. All procedures were done in single stage in group-B. Telecanthus and Epicanthus inversus were corrected by $\mathrm{Y}-\mathrm{V}$ Plasty in group $\mathrm{A}$ and $\mathrm{C}-\mathrm{V}$ plasty in group-B. Ptosis were corrected by Frontalis Brow Suspension (FBS) with preserved or autologous Fascia Lata after three months of Y-V Plasty. Lateral canthotomy and canthoplasty was done to maintain normal horizontal palpebral fissure.

\section{Clinical Diagnosis}

The diagnosis of blepharophimosis syndrome (BPES) is based on the clinical findings, which are present at birth. Narrowing of the horizontal aperture of the eyelids causes blepharophimosis. The horizontal palpebral fissure measures 28-30 $\mathrm{mm}$ in normal adult.

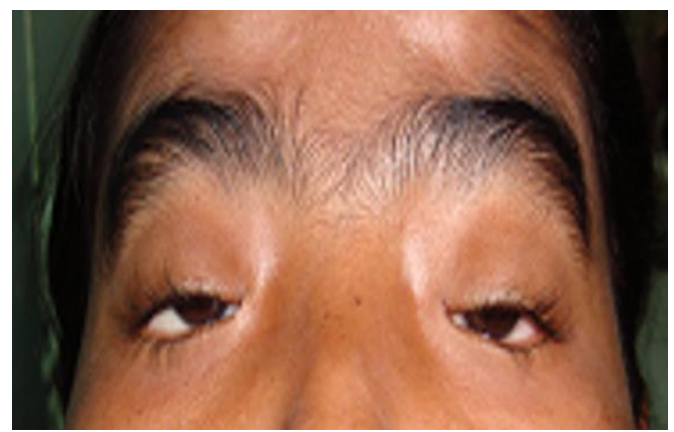

Fig. 1: BPS type 1

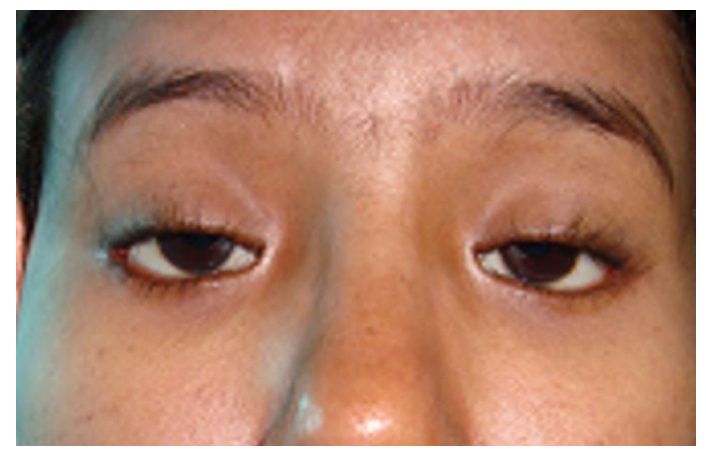

Fig. 2: BPS type 2

Blepharophimosis syndrome is classified into two types- BPES type I includes ptosis, telecanthus and epicanthus inversus. BPES type II include Ptosis, telecanthus and Lateral ectropion. ${ }^{1-5}$

\section{Results}

We evaluated fifty patients of Blepharophimosis syndrome. Male patients were $21(42 \%)$ and female patients were 29 
$(58 \%)$. The range of the age of these patients were $3 \mathrm{yrs}$ to 42 yrs. The mean age of the study subjects was 21.35 years. In group-A, all patients were treated as two stage surgery. 31 patients showed postoperative acceptable result and four patients presented unsatisfactory correction of Telecanthus. Revision was planned in 01 female patient but she did not follow up. Among 31 patients, 01 patient required lazy $\mathrm{T}$ procedure for correction of punctal eversion. Undercorrection after ptosis surgery was observed in 02 patients. In group-B, 14 patients showed satisfactory outcome of $\mathrm{C}-\mathrm{V}$ plasty and undercorrection was observed in 4 patients followed by ptosis surgery. Initial skin scarin was found in 14 cases of total.

\section{Discussion}

We corrected telecanthus and epicanthus by $\mathrm{Y}-\mathrm{V}$ plasty in 35 cases. Ptosis correction were done after three months of primary surgery. Lateral canthoplasty were corrected in some cases. New approach $\mathrm{C}-\mathrm{V}$ plasty were done in fifteen cases to correct telecanthus and epicanthus. Lateral canthoplasty and frontalis brow suspension were done at same sitting. The result of $\mathrm{Y}-\mathrm{V}$ plasty and $\mathrm{C}-\mathrm{V}$ plasty were same but ptosis surgery was resulted better in separate approach after three months of first surgery. Under correction was observed in ptosis surgery in six cases.

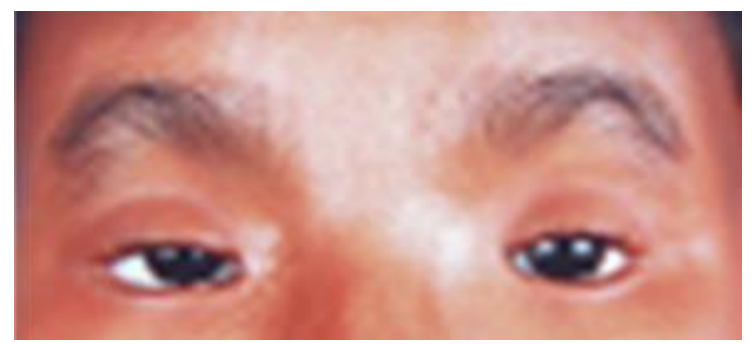

Fig. 3: Preoperative

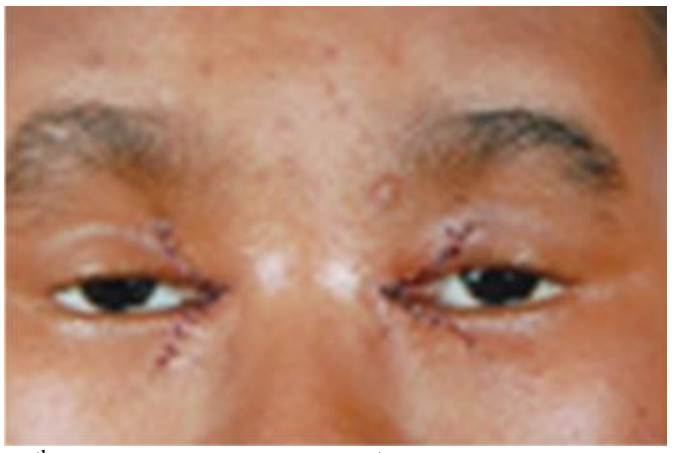

Fig. 4: $7^{\text {th }}$ POD of Y-V plasty ( $1^{\text {st }}$ stage $)$

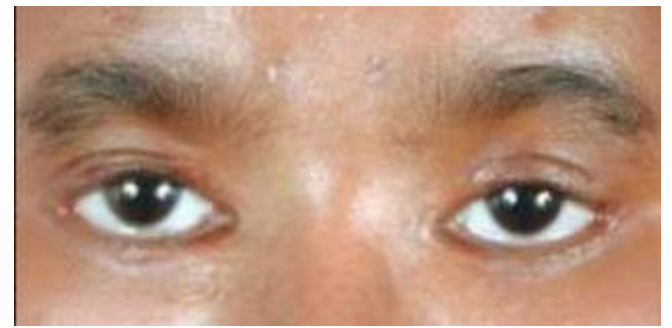

Fig. 5: After $2^{\text {nd }}$ stage surgery (FBS)

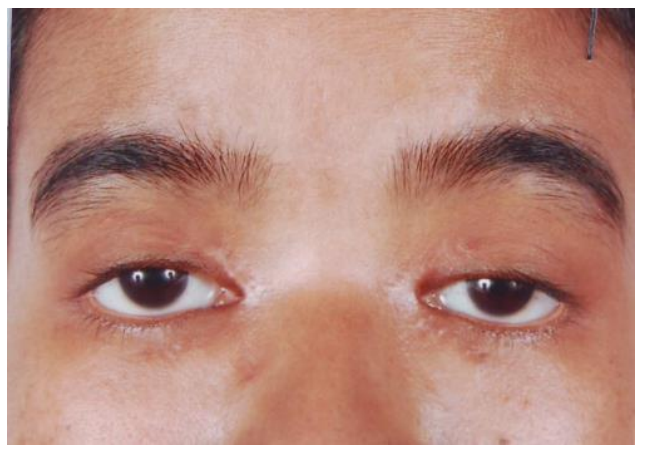

Fig. 6: Preoperative photograph of $\mathrm{Y}-\mathrm{V}$ plasty

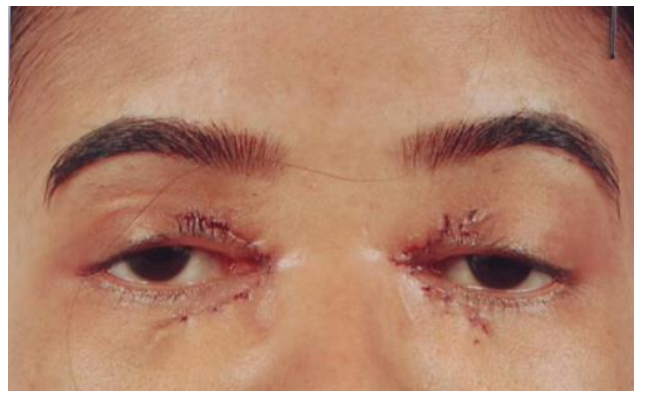

Fig. 7: 7th POD of 1st stage surgery- Y-V plasty

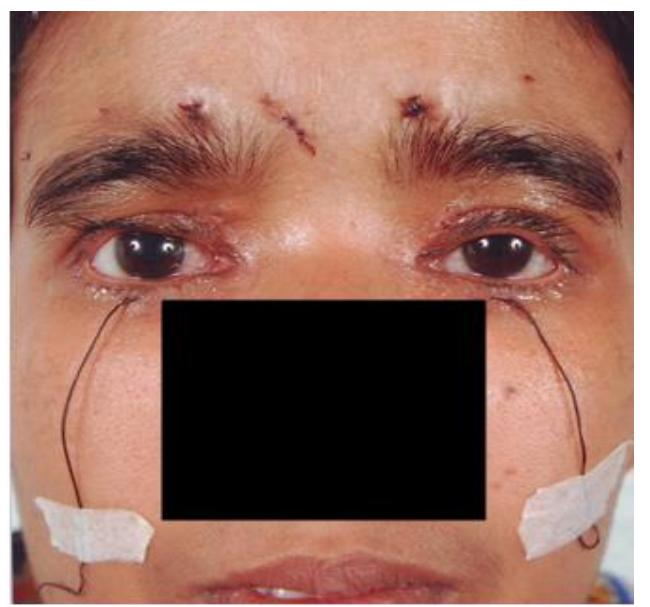

Fig. 8: After 2nd stage surgery (FBS) of BPES

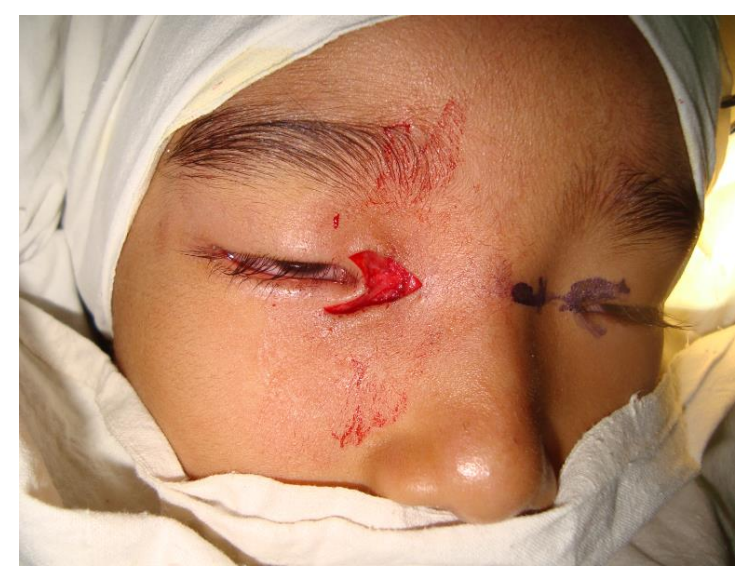

Fig. 9: Peroperative photograph of $Y-V$ plasty 


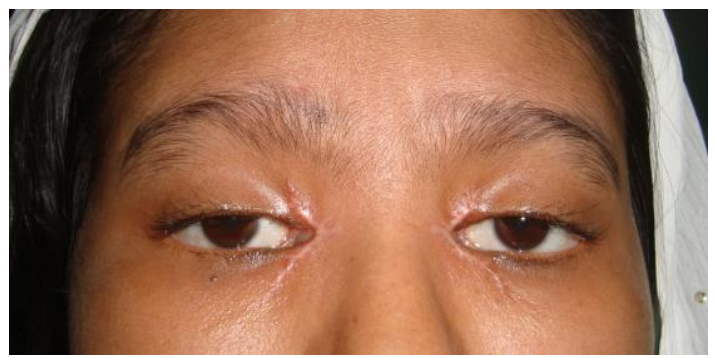

Fig. 10: Skin scars

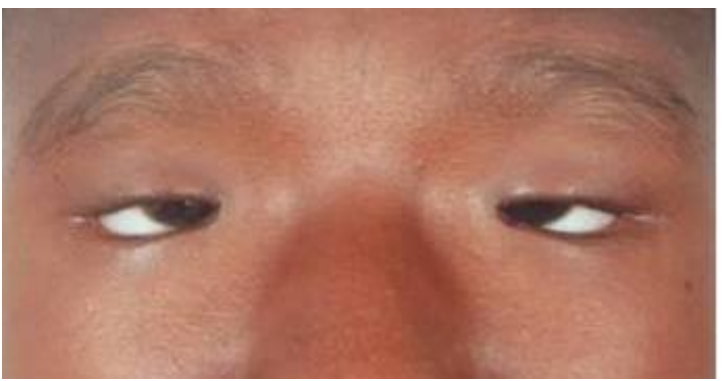

Fig. 11: BPES- preoperative photgraph of C-V plasty + FBS

The one-stage corrective procedure provided acceptable results both in function and cosmesis. 18 out of $23(78 \%)$ patients underwent one-stage surgery before the age of 5 years. Only two patients had a blepharophimosis ratio greater than 1.5 as poor result. Two out of $18(11 \%)$ patients with PFHs more than $2 \mathrm{~mm}$ needed a repeat operation, but all five $(100 \%)$ patients with less than $2 \mathrm{~mm}$ (very severe ptosis) needed repeat operations. ${ }^{6}$ A total of 11 patients $(8$ males, 3 females) with a mean age of 9 years (range 6--22 years) were reviewed. The surgical outcome was assessed both functionally and cosmetically in single stage surgery. The mean preoperative visual acuity was $0.729 \pm 0.316 \mathrm{SD}$ and the mean postoperative visual acuity was $0.856 \pm 0.277$ SD $(P$ <0.0428). There was a statistically significant improvement of telecanthus $(P<0.0001)$ in terms of inner intercanthal distance, and horizontal palpebral fissure length $(P=0.019)$. The mean preoperative and postoperative intracanthal distance was $3 \pm 0.33 \mathrm{SD}$ and $2.418 \pm 0.189 \mathrm{SD}$, respectively. There was also a significant postoperative improvement of ptosis $(P<0.01)$. All the patients had a stable functional and cosmetic result after a mean follow-up period of 3 years. ${ }^{7}$ Kuhn has suggested modifying the incision used in $\mathrm{Y}-\mathrm{V}$ plasty to a $\mathrm{C}$-shaped, so that it conforms the Langers skin fold and further reduces the scarring postoperatively.

\section{Conclusion}

There is no significant difference between $\mathrm{Y}-\mathrm{V}$ plasty and $\mathrm{C}-\mathrm{V}$ plasty to correct telecanthus and epicanthus. Ptosis correction resulted well in separate sittings.

\section{Acknowledgment}

The authors thank Professor Subrahmanyam Mallajosyula, professor and head, department of Ophthalmology, Maharaja Institute of Medical Sciences, India and Professor Golam Haider, Director, Medical Education, Bangladesh Eye Hospital and Institute, Dhaka, Bangladesh for guide and inspire me to do research work and academic activities.

\section{Conflict of Interest: None.}

\section{References}

1. Allen CE, Rubin PA. Blepharophimosis -ptosis-epicanthus inversus syndrome (BPES): clinical manifestation and treatment. Int Ophthalmol Clin 2008;48(2):15-23.

2. Mukherjee B, Alam MS. Double Jeopardy: Blepharophimosis Syndrome with Congenital Nasolacrimal Duct Obstruction in Twins. Orbit 2013;32(5):318-20.

Beckingsale PS, Sullivan TJ, Wong VA, Oley C.

Blepharophimosis: a recommendation for early surgery in patients with severe ptosis. Clin Exp Ophthalmol 2003;31:13842.

3. Choi KH, Kyung S, Oh SY. The factors influencing visual development in blepharophimosis-ptosis-epicanthus inversus syndrome. J Pediatr Ophthalmol Strabismus 2006;43:285-8.

4. Dawson EL, Hardy TG, Collin JR, Lee JP. The incidence of strabismus and refractive error in patients with blepharophimosis, ptosis and epicanthus inversus syndrome (BPES). Strabismus 2003;11:173-7.

5. S-Y Wu, L Ma, Y-J Tsai, J Z-C Kuo. One-stage correction for blepharophimosis syndrome. Eye 2008;22:378-88.

6. Huang WQ, Qiao Q, Zhao R, Wang XJ, Fang XQ authors. Surgical strategy for congenital blepherophimosis syndrome. Chin Med J 2007;120:1413-5.

How to cite this article: Kadir SMU. Surgical outcome of blepharophimosis syndrome: Double vs single stage. Int J Ocul Oncol Oculoplasty 2019;5(2):80-2. 